\author{
Military Technical College \\ Kobry El-Kobbah, \\ Cairo, Egypt.
}

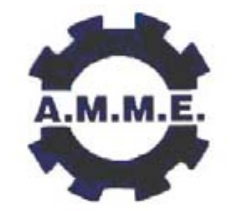

$13^{\text {th }}$ International Conference on Applied Mechanics and Mechanical Engineering.

\title{
APPLICATION OF CFD TECHNIQUE FOR ASSESEMENT OF ROAD TUNNEL VENTILAION
}

\author{
$\operatorname{HAMAD}^{*}$ S.Y., IBRAHIM ${ }^{* *}$ A. G. And ELSHAMARKA** S. E.
}

\begin{abstract}
The most recent technique to study the behavior of tunnel ventilation is computational fluid dynamics (CFD). This approach is capable of modeling the multi-dimensional, obstructed and non-obstructed tunnels of arbitrary geometry. This paper addressed the methodology improvement for the design of ventilated road tunnels using CFD technique. A comprehensive CFD simulation has been carried out to examine the velocity, pressure and temperature distributions in the main scenario of tunnel ventilation in case of normal and halted traffic. The predicted results are used to enhance the design and evaluate the ventilation system capability to fulfill the required thermal environment inside the tunnel. The base design of tunnel ventilation system was modified to avoid the unsafe regions in the tunnel where the effects of carbon monoxide (CO) are hazard.
\end{abstract}

\section{NOMENCLATURE}

$\begin{array}{ll}\text { CFD } & \text { Computational Fluid Dynamics } \\ \text { CO } & \text { Carbon monoxide } \\ k & \text { The turbulence energy } \\ \text { LES } & \text { Large Eddy Simulation } \\ \text { MTFVTP } & \text { Memorial Tunnel Fire Ventilation Test Program } \\ \text { MVS } & \text { Mechanical ventilation systems } \\ \mathrm{NO}_{\mathrm{x}} & \text { Oxides of Nitrogen } \\ \mathrm{NRC} & \text { National Research Council } \\ \mathrm{RANS} & \text { Reynolds-averaged Navier-Stokes } \\ \mathrm{SES} & \text { Subway Environmental Simulation } \\ \mathrm{SO}_{2} & \text { Sulfur dioxide } \\ \boldsymbol{\varepsilon} & \text { The rate of viscous dissipation of turbulence energy } \\ \omega & \text { The turbulence dissipation rate }\end{array}$

* Syrian Armed Forces

** Egyptian Armed Forces 


\section{INTRODUCTION}

All road tunnels require ventilation to maintain acceptable levels of contaminants produced by vehicle engines during normal traffic operation (normal ventilation). This ventilation must also act to remove and control heavy smoke and hot gases during a fire emergency (emergency ventilation). Road tunnels can be classified in terms of the type of ventilation system: natural and mechanical ventilation systems (MVS). There are different MVS layouts used in road tunnels, longitudinal, transverse, and semi transverse. The choice of a ventilation system to use depends on several parameters that include: tunnel dimensions, location, orientation, grade, traffic load, and construction limitations. Establishing air requirements for the roadway tunnel and consequently the capacity of the MVS is challenging due to the difficulty of controlling many variables, such as the possibility of various traffic patterns. Methods of controlling air contaminants and smoke from fire in a tunnel include longitudinal flow, extraction and dilution.

Over the past three decades, computational fluid dynamics CFD has been increasingly used for a wide variety of engineering applications [1 ]. In such applications, computational modeling allows to perform simulations of complex problems, investigate the effect of different design parameters, obtain detailed distributions of all relevant variables, and gain insight into the underlying physical processes. By a proper use of modeling, one can cut down on time consuming and costly experiments and field measurements. The purpose of this paper is to describe the applications of CFD to the problem deals with ventilation in road tunnels. Numerical simulation can play an important role in the understanding and design optimization of road tunnels ventilation. Turbulent flow is the dominant flow pattern in MVS used in road tunnels. A major difference among turbulent models used in CFD is how the Reynolds stress viscosity used in the momentum equation is calculated. There are two alternative methods that can be employed to transform the Navier-Stokes equations in such a way that the small-scale turbulent fluctuations do not have to be directly simulated: Reynolds-averaged Navier-Stokes (RANS) and Large Eddy Simulation (LES) [2].

The RANS turbulence models approximate the turbulent energy and dissipation produced by the flow. This approach results in a steady-state solution to an averaged version of the flow equations. The Reynolds-averaged approach is generally adopted for practical engineering calculations, and uses models such as Spalart-Allmaras, $k-\varepsilon$ and its variants, $k-\omega$ and its variants, and the Reynolds stress model (RSM).

On the other hand, LES provides an alternative approach in which the large eddies is computed in a time-dependent simulation that uses a set of "filtered" equations. Filtering is essentially a manipulation of the exact Navier-Stokes equations to remove only the eddies that are smaller than the size of the filter, which is usually taken as the mesh size. The LES approach results in a transient solution to the Navier-Stokes equations. Because real turbulent flow situations are inherently transient, LES methods can have an advantage in modelling turbulent fire-induced flows.

Numerical modelling approaches can be further classified as one-, two- and threedimensional modelling. One-dimensional models, such as the Subway Environmental Simulation (SES) computer program, provide simple design tools. SES can be used to 
examine the longitudinal airflow in a road tunnel [3], [4]. While TUNVEN [5] program solves the coupled one-dimensional steady-state tunnel aerodynamic and convection equations. It can predict quasi-steady-state longitudinal air velocities and the concentrations of carbon monoxide $\mathrm{CO}$, oxides of nitrogen $\mathrm{NO}_{x}$, and total hydrocarbons along a highway tunnel for a wide range of tunnel designs, traffic loads, and external ambient conditions. The program can model all common ventilation systems (natural, longitudinal, semi-transverse, and transverse).

Kashef et al. [6] presented interim findings of a collaborative research project conducted at the National Research Council (NRC) of Canada. The objective of work was to evaluate the effectiveness of the emergency ventilation systems in road tunnels. They presented comparisons of the results, experimental and computational investigations were conducted on a semi-transversal underwater road tunnel. The CFD predictions made using SOLVENT $^{\circledR}$ [7] showed a fair agreement with the experimental data. SOLVENT ${ }^{\circledR}$ was developed and validated as a customized CFD code specifically for tunnel application during phase IV of the Memorial Tunnel Fire Ventilation Test Program (MTVTP) work [8].

Also, Li and Chow [9] performed numerical simulation using CFD models on performance evaluation of tunnel ventilation systems. The predictions from PHONICS ${ }^{\circledR}$ CFD codes were conducted to different ventilation systems. Systems considered were longitudinal, semitransverse, transverse, partial transverse and combined longitudinal and semi-transverse.

Finally, Tajadura et al. [10] investigated the influence of the slope in the semi-transversal ventilation system of an urban tunnel. The numerical model was performed with FLUENT ${ }^{\circledR}$ to solve 3-diemnsional Navier-Stockes equations. Turbulence was simulated with the standard $\boldsymbol{k}-\boldsymbol{\varepsilon}$ model.

In this paper, the CFD technique is used to check a base design of ventilation system of road tunnel in the main scenario of operation. The thermal environment inside the road tunnel for different traffic patterns is simulated. Based on simulation results, the configuration of ventilation system was modified to enhance the air flow pattern and avoid hazard concentration of pollutants in all regions inside the road tunnel.

\section{THE PROBLEM CONSIDERED}

The main air pollutants from road traffic are: $\mathrm{CO}$ from petrol and diesel engines, smoke (carbon particles) particularly from larger diesel engines, $\mathrm{NO}_{\mathrm{x}}$ (nitrogen monoxide and nitrogen dioxide). Being exposed to emergency fire, smoke or even normal engine emissions such as $\mathrm{CO}$, and diesel smoke the health and safety of passengers are of utmost importance. The capacity and size of the ventilation equipment installed in a tunnel are often dictated by the maximum concentration limit for these pollutants, as set by international standards [11], [12], [13].

A successful tunnel ventilation system must limit the unpleasant smoke and smell characteristics of heavy vehicle exhausts. Although it is required to keep the recommended maximum 8- hour day exposures being: 25 ppm NO; 5 ppm NO 
$\mathrm{SO}_{2}$ with present day engine designs. It is noticed that these values will not be reached until $\mathrm{CO}$ content is as high as $500 \mathrm{ppm}$ due to recent efficient engine design, [ 14 ]. Hence, design of road tunnel ventilation system may be based on carbon monoxide dilution

The underlying tunnel of $2 \mathrm{~km}$ long with two-ways of unidirectional two lanes was simplified as rectangular tube with cross-section of $5 \mathrm{~m}$ height and $8 \mathrm{~m}$ width. The road tunnel slope was divided to three sections as following: $-4 \%$ for $700 \mathrm{~m}, 0 \%$ for $600 \mathrm{~m}$, and $+4 \%$ for 700 $\mathrm{m}$. Figure (1) shows configuration of the road tunnel. More relevant data of the tunnel and the detailed design of ventilation system of the underlying tunnel is reported elsewhere [15].

The tunnel ventilation is provided by a transverse system with local extraction points at which polluted air is extracted. Exhaust shafts are located at interval of $100 \mathrm{~m}$. They extract vehicle emissions and expel outside. Eighteen axial flow fans arranged in nine batteries (2 fans for each battery) supply air through side openings uniformly distributed along one wall for each roadway. They are situated in one row located at height of $1.0 \mathrm{~m}$ above the tunnel floor, and at intervals of $6 \mathrm{~m}$. Uniform distribution of air throughout the length of the tunnel is the main characteristic of the selected ventilation system. The supply air version of this system produces a uniform level of carbon monoxide throughout the tunnel because the air and the vehicle exhaust gases enter the roadway area at the same rate. This will satisfy the fresh air needed for the dilution of $\mathrm{CO}$ and avoid any dead zone along the tunnel. Figure (2) shows the general layout of the ventilation system for a $50 \mathrm{~m}$ segment of the central section of the tunnel.

\section{THE COMPUTATIONAL MODEL}

\section{General}

The study of the airflow patterns, velocity distribution, temperature distribution, and pressure distribution was carried out, by means of the solution of the differential equations of conservation of mass, momentum and energy, complemented by turbulent flow models. Calculations were performed with a commercial software package FLUENT ${ }^{\circledR}$ [16]. This code uses the finite volume method and solves the three-dimensional Navier-Stokes equations on a variety of grid geometries. The airflow pattern inside road tunnel through used transverse ventilation system is considered as turbulent, steady, and incompressible with heat transfer. The solutions consisted basically of three-dimensional fields of the flow variables: velocity (magnitude and direction), static pressure, and temperature.

\section{Governing Equations}

There are three groups of basic equations, which are derived from three basic physics laws of conservation: the mass conservation, momentum conservation and energy conservation. It results in the continuity equation, Navier-Stokes equation and energy equation, respectively. The employed mathematical model solved numerically the 
governing equations for the velocity vectors, pressure, temperature, and turbulence parameters.

The standard $\boldsymbol{k}-\boldsymbol{\varepsilon}$ turbulence model was used to model the turbulent flow inside the road tunnel. The standard $\boldsymbol{k}-\boldsymbol{\varepsilon}$ model is a semi-empirical model based on model transport equations for two variables: $\boldsymbol{k}$ the turbulence energy, and $\boldsymbol{\varepsilon}$ the rate of viscous dissipation of turbulence energy. The model transport equations for $\boldsymbol{k}$ and $\boldsymbol{\varepsilon}$ are reported in [17], [18].

\section{Solution Domain and Grid Resolution}

The procedure began with the geometric definition of the numerical domain. Due to similarity the studying was achieved for one way. As the tunnel is very long, only a segment of length $100 \mathrm{~m}$ was considered. Geometry creation and mesh generation have been undertaken using the pre-processor software package GAMBIT ${ }^{\circledR}$. A Cartesian coordinate grid system was assigned along the $\mathrm{x}, \mathrm{y}$ (vertical) and $\mathrm{z}$ directions as shown in Figure (3). Once a grid has been exported into the program, all remaining operations are performed within the solver. These include setting boundary conditions, defining fluid properties, executing this solution, refining the grid, and viewing and post processing the results. Numerical simulations have been performed on central part of the underlying road tunnel, for two possible cases of the main scenario for the tunnel ventilation system: normal and halted traffic pattern. The following simplifications were made during the CFD simulations:

(1) The ventilation flow has been modeled by setting the flow of air at the tunnel inlet uniformly through out the whole cross-sectional area.

(2) The tunnel wall was modeled as insulation wall therefore no heat loss was considered.

(3) It is assumed that the flow is symmetrical about the tunnel vertical mid-plane.

\section{Normal traffic pattern}

First, numerical simulations have been performed to a segment with $100 \mathrm{~m}$ length $(x=100$ $\mathrm{m}, \mathrm{y}=5 \mathrm{~m}, \mathrm{z}=8 \mathrm{~m})$ for the central section of the tunnel that is straight and flat. There are 80 inlet $(1 \times 0.2 \mathrm{~m})$ for fresh air supply $(40$ for every side), one outlet $(3 \times 2 \mathrm{~m})$ for exit the pollution air at the center of the tunnel ceiling.

Based on simulated results, the spacing between exhaust shafts were shortened to $50 \mathrm{~m}$ only instead of $100 \mathrm{~m}$. Hence, the numerical simulations have been performed for $50 \mathrm{~m}$ length $(x=50 \mathrm{~m}, y=5 \mathrm{~m}, z=8 \mathrm{~m}$ ) with 40 inlet for fresh air supply (20 for every side).

Due to the geometrical symmetry, the domain of solution was limited to the quarter of the tunnel segment. The tunnel is represented in the CFD field model by a structured Cartesian coordinate. The uniform grid consisting of 80 cells in the cross section direction. Vertical and longitudinal grids were set at 100 cells and 200 cells, respectively. There are various types of cells, which can be used for meshing purpose. The available threedimensional cell types are tetrahedral, hexahedron, prism as well as pyramid. The hexahedron cell has been chosen. The grid used for each case has a total of 1,600,000 cells. Figure (3) shows the mesh of the whole segment. 


\section{Halted traffic pattern}

Geometry in case of halted traffic is similar to geometry in case of normal operation but 12 vehicles added inside the tunnel for studying heat interaction and to predict temperature distribution, Figure (4). Typical dimensions of the car are taken to be $1.5 \mathrm{~m}$ in width, $5 \mathrm{~m}$ in length and $1.5 \mathrm{~m}$ in height. Figure (5) shows the details of the mesh in the vicinity of the vehicle.

\section{Boundary Conditions}

The boundary conditions at the supply/exhaust openings were derived from the design calculations of ducting system for the ventilation system.

\section{Normal traffic pattern}

1. For all inlets; flow rates: $0.5 \mathrm{~m}^{3} / \mathrm{s}(0.6 \mathrm{~kg} / \mathrm{s})$, pressure $=370 \mathrm{~Pa}$ gauges pressure and temperature $=300 \mathrm{~K}$.

2. Turbulent intensity $=3 \%$.

3. Outflow for outlet $24 \mathrm{~kg} / \mathrm{s}$.

4. Outside walls is treated as wall (no slip conditions), with no heat flux.

5. Symmetry for end walls.

6 . The thermo-physical properties of interior air were taken at $300 \mathrm{~K}$.

\section{Halted traffic pattern}

Similar to the case of normal traffic with the addition of new wall for surfaces of the vehicles being in the tunnel,

1. Surfaces temperature $=343 \mathrm{~K}$.

2. Hear transfer coefficient $h$ was calculated $=9 \mathrm{~W} / \mathrm{m}^{2} \mathrm{~K},[14]$.

3. Heat release for every vehicle $Q=100 \mathrm{~kW}$.

\section{Computing Platform}

The numerical results were obtained using PC with Pentium $4(3.0 \mathrm{GHz})$ processor, 512 MB RAM and 80GB hard disk memory. Generally, 300 iterations were required to obtain a suitable level of solution convergence, while each run requires about 3 hours of CPU time and about $300 \mathrm{MB}$ of hard disk memory. The accuracy in the CFD simulation is obtained in terms of residual. Residual is the measurement of the error. The residual must be kept on decreasing from the start to end of the iterations. Thus, the solution is converged. If the residual through iterations have increased, the solution would diverge. Value of the residual was chosen 0.001 .

\section{RESULTS AND DISCUSSIONS}

As previously stated, the numerical solutions provided three-dimensional fields of the flow variables. In order to illustrate the effects of the different traffic patterns on the behavior of the ventilation system, the longitudinal profiles of flow variables along a central plane in tunnel segment will be shown. The normal breathing height inside the tunnel was $1 \mathrm{~m}$ for the passengers and $2 \mathrm{~m}$ for the tunnel users. Therefore, the results are presented at these 
levels $y=1$ and $2 \mathrm{~m}$. Due to the geometrical symmetry; the results are shown on the quarter part of the tunnel segment.

\section{Normal Traffic Pattern (Design conditions)}

In general the air flow inside the tunnel should be movable in all regions without any dead zones (velocity $<0.2 \mathrm{~m} / \mathrm{s}$ ) to avoid the unsafe regions in the tunnel where the effects of the $\mathrm{CO}$ are hazardous.

The behavior of the airflow in the tunnel plays a major role in determining the longitudinal and vertical air velocity and, consequently, the ability of a ventilation configuration to maintain an acceptable level for $\mathrm{CO}$ and guarantee under all circumstances a low concentrations of all pollutants and a sufficient visibility level.

Figure (6) represents the air velocity at height $1 \mathrm{~m}$ and $2 \mathrm{~m}$ for the base design of ventilation system. There are unsafe regions inside the tunnel with velocity values less than $0.2 \mathrm{~m} / \mathrm{s}$. Figure (7) represents the general flow pattern in the tunnel module with contour values. Different colors represent different velocity magnitudes in Figure (8). Poor airflow pattern with the hazard of high $\mathrm{CO}$ concentration especially at $1 \mathrm{~m}$ height was recognized.

Though the ventilation system was designed to supply the proper quantity of fresh air to dilute the pollution level inside the tunnel to a safe level and bring fresh air in from outside, the simulated results of flow pattern indicates dead zones. Two alternatives to modify the ventilation system were available. Either to reduce the exhaust shafts intervals or to reduce size of supply openings. The first one was chosen.

Figure (9) shows the air velocity at height $1 \mathrm{~m}$ and $2 \mathrm{~m}$ for $50 \mathrm{~m}$ exhaust shaft intervals. The velocities in the modified ventilation system were in order of $0.8 \mathrm{~m} / \mathrm{s}$, which is higher and less fluctuating than the velocities that existed in base ventilation system. The exhaust fan located in the ceiling caused the velocities at $y=2 \mathrm{~m}$ to be more fluctuating than those at $\mathrm{y}=1 \mathrm{~m}$.

Figure (10) represents the general flow pattern in the tunnel segment for the modified design. There are no unsafe regions inside the tunnel that indicates an efficient ventilation system and successful design. In Figure (11) the airflow pattern is represented by contours of the velocity field. The air supplied through the side wall openings created regions of high velocities. Furthermore, the exhaust fan located at the ceiling resulted in higher velocities at the top of the tunnel.

The average velocities at different vertical cross-sections along the tunnel are shown in Figure (12). The CFD simulations have captured the features of the velocity profiles. It is also clearly shown a relatively high velocity of approximately $0.7 \mathrm{~m} / \mathrm{s}$ in the region $0.8-2$ $\mathrm{m}$ above the floor.

Figure (13 a) shows the velocity vectors obtained in a longitudinal plane at the center of the tunnel; it shows air movement towards the top of the tunnel and towards the outlet 
without eddies or circulating flows. This leads the fresh air at vehicle passenger level will satisfy dilution for $\mathrm{CO}$ therefore there are no unsafe regions. A uniform velocity distribution is shown in Figure (13 b) at vertical cross-section in the middle of tunnel segment.

Pressure distribution in the longitudinal plane through the centerline of road tunnel segment is shown in Figures (14) and (15). Pressure contours indicate a uniform distribution along the tunnel. The legend on the left shows the values of the pressure. The shown results ensure that the pressure is stable and equal throughout the tunnel.

The prior results, Figures (9) - (15), indicate that the modified design of ventilation system is successful and efficient.

\section{Halted Traffic Pattern}

The modified design of ventilation system is checked in case of halted traffic pattern. In the halted traffic the larger number of vehicles will increase the total drag resistance to air movements and the temperature will increase too at total heat release rate $300 \mathrm{~kW}$ (for the solution domain).

Figure (16) shows temperature distribution around the vehicles at vertical cross-section at middle of the tunnel segment $(x=12.5 \mathrm{~m})$ for the two ways, and Figure (17) shows CFD predicted temperature distribution around one vehicle. From the prior figures the following are observed, the air temperature decreases gradually from surface of the vehicles to outwards with higher values (in red) corresponding to $343 \mathrm{~K}$ and lower values (in dark blue) corresponding to $305 \mathrm{~K}$.

Figure (18) shows longitudinal plane at middle of the tunnel as no vehicles in this plane and the temperature distribution is uniform. Within a small distance away from the vehicle, the temperatures were uniform and ambient. The maximum temperature recognized was approximately $343 \mathrm{~K}$.

All prior results indicate that the tunnel ventilation system is successful and efficient in case of halted traffic.

The airflow pattern and air velocity at $\mathrm{y}=1 \mathrm{~m}$ for the second traffic pattern is shown in Figure (19). The air velocity at mid-tunnel decreased from almost $0.8 \mathrm{~m} / \mathrm{s}$ (corresponding to normal traffic pattern) to $0.5 \mathrm{~m} / \mathrm{s}$ because the vehicles represent obstacles to the air movement. Though the drop in air velocity for halted traffic pattern, the air flow pattern is still far from the formation of dead zones.

Figures (20) and (21) shows pressure distribution across the longitudinal plane passing through the centerline of the tunnel. The shown results indicate no big change in pressure distribution compared with the first traffic pattern. 


\section{CONCLUSIONS}

CFD is now a popular design tool for engineers from different disciplines due to the high cost, complexity, and limited information obtained from experimental methods. Tunnel ventilation system design can be developed in depth from the predictions of various parameters, such as air velocity. Different ventilation configurations can be analyzed by CFD without the need to perform the actual tests. CFD simulations on tunnel were presented. Simulation results, for different traffic patterns, were used to check thermal environment, i.e. velocity, pressure and temperature, inside the road tunnel. The spacing intervals between exhaust shafts in the base design of ventilation system were reduced to ensure acceptable air flow pattern in all regions inside the road tunnel. The modified design of ventilation system avoids dead zones and possibility of hazard concentration of $\mathrm{CO}$ for the main scenario of operation. This enhanced design is taken as an initial step for forward analysis of the emergency scenario of tunnel ventilation, i.e. in case of fire.

\section{REFERENCES}

1. Patankar, S. V, "Computational Modeling of Flow and Heat Transfer in Industrial Applications", Int. J. Heat and Fluid Flow, (23) p. 222-231, 2002.

2. Gao, P.Z.; Liu, S.L.; Chow, W.K. and Fong, N.K.; " Large Eddy Simulation for Studying Tunnel Smoke ventilation"”; Tunnelling and Underground Space Technology, (19), p. 577-586, 2004.

3. "Subway Environment Simulation (SES) computer program Version 4: User's Manual and Programmer's Manual", Issued as Volume II of Subway Environmental Design Handbook, US Department of Transportation, Washington, DC, USA, 1997.

4. Parsons Brinkerhoff Quade and Douglas, Inc., "Validation and Enhancements to the Subway Environment Simulation (SES) Computer Program Fire Model", Volpe Transportation Systems Center, USA, 1997.

5. NTIS, "User's guide for the TUNVEN and DUCT programs", Publication PB80141575. National Technical Information Service, Springfield, VA, USA, 1980.

6. Kashef, A; Benichou, N; Lougheed, G.; and Debs, A; "Numerical Modeling of Air Movement in Road Tunnels", Proceeding of $11^{\text {th }}$ Annual Conference of the Computational Fluid Dynamics, Vancouver, Canada, p. 23-30, 2003.

7. Innovative Research, Inc. and Parsons Brinkerhoff, Inc., "SOLVENT Version 1.0", 2000.

8. MHD and FHWA, "The Memorial Tunnel Fire Ventilation Test Program", Massachusetts Highway Department and Federal Highway Administration, ASHRAE Transactions: Symposia, 1997.

9. Li, S. M. and Chow, W. K.; "Numerical Studies on Performance Evaluation of Tunnel Ventilation Safety Systems"; Tunnelling and Underground Space Technology, (18), p. 435-452, 2003. 
10. Tajadura, R. B.; Morros, C. S. and Marigorta, E. B.; "Influence of the Slope in the Ventilation Semi-transversal System of an Urban Tunnel"; Tunnelling and Underground Space Technology, (21), p. 21-28, 2006.

11. ASHRAE Handbook, HVAC Applications, "Enclosed Vehicular Facilities", Chapter 12, American Society of Heating Refrigeration and Air conditioning Engineers, Atlanta, USA, 1999.

12. NFPA, "502 Standard for Road Tunnels, Bridges, and Other Limited Access Highways", National Fire Protection Association, Quincy, MA, USA, 2001 Edition.

13. PIARC, "Fire and Smoke Control in Road Tunnels", Permanent International Association of Road, Committee on Road Tunnels (C5), 1999.

14. John O. Bickel and T. R. Kuesel; "Tunnel Engineering Handbook", $3^{\text {rd }}$ edition, Van Nostrand Reinhold Company Inc, 1995.

15. Hamad, S. Y.; "A Study of Thermal Environment inside a Road Tunnel"; MSc Thesis, MTC, Cairo, Egypt, 2006.

16. FLUENT ${ }^{\circledR} 6.2$ Documentation, Fluent Inc. 2005.

17. Anderson, D.A; Tannehill, J.C; and Pletdher, R, H.; "Computational Fluid Mechanics and Heat Transfer", Taylor and Francis, second edition, 1997.

18. Launder, B. E., and Spalding, D. B., "Mathematical Models of Turbulence", Academic press, London, 1972. 


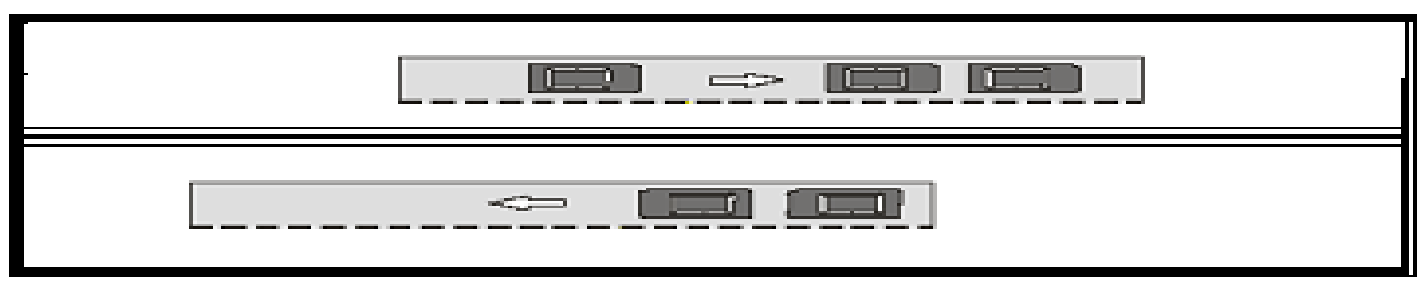

a- Plan

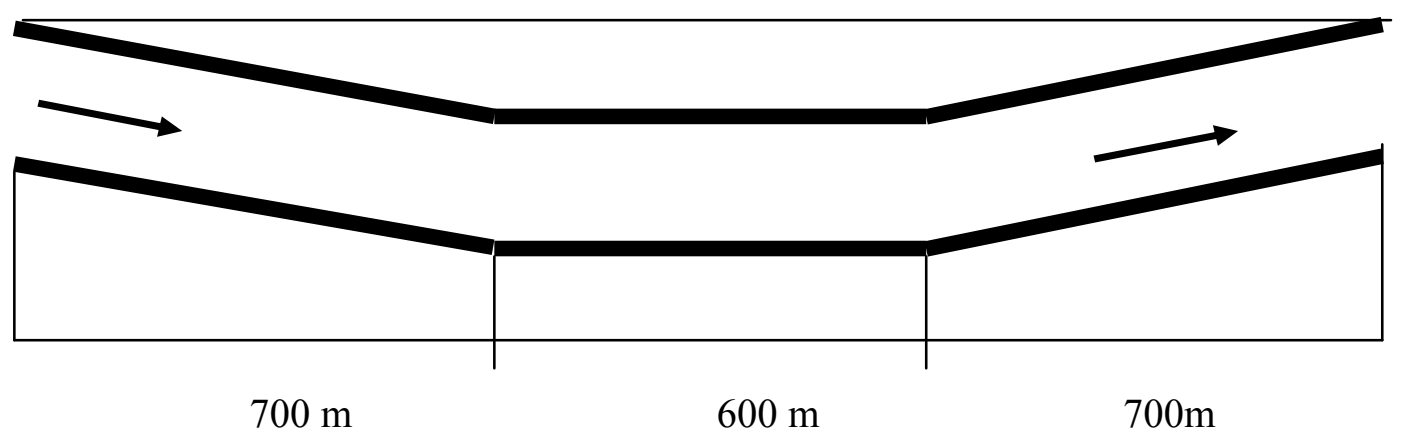

b- Elevation

Fig (1) Configuration of underlying road tunnel

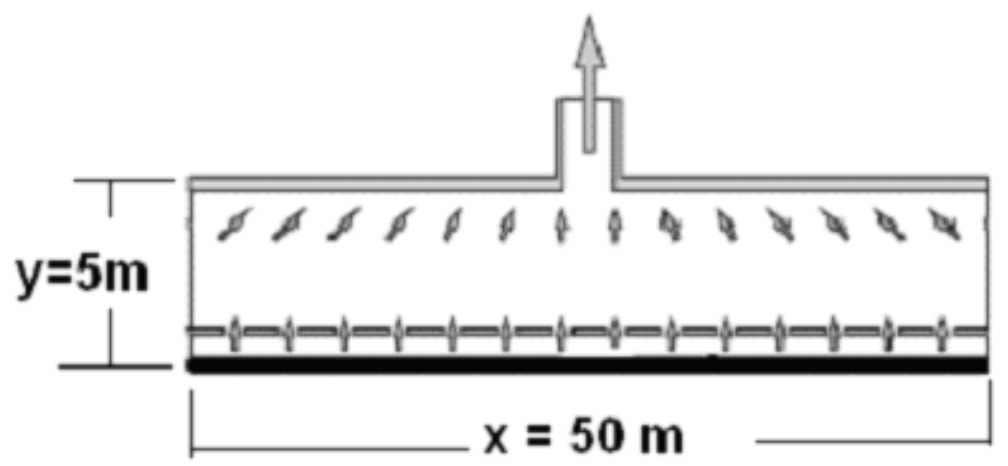

supply shaft

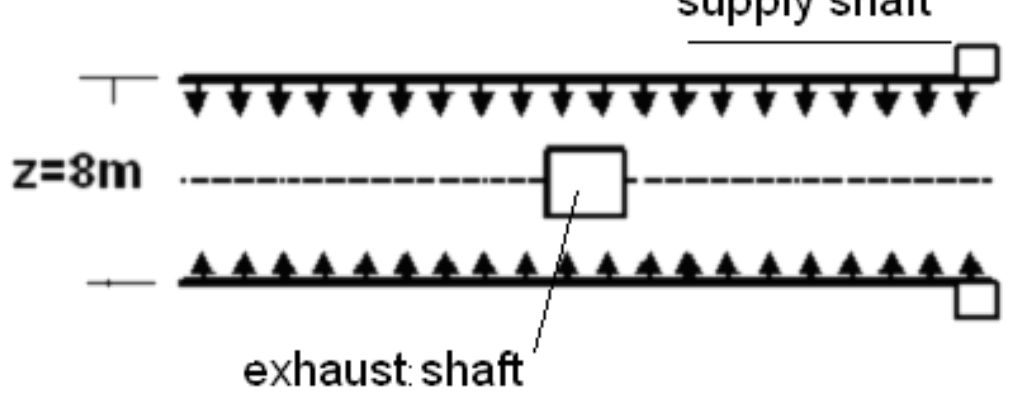

Fig (2) General layout of ventilation system for $50 \mathrm{~m}$ tunnel segment 


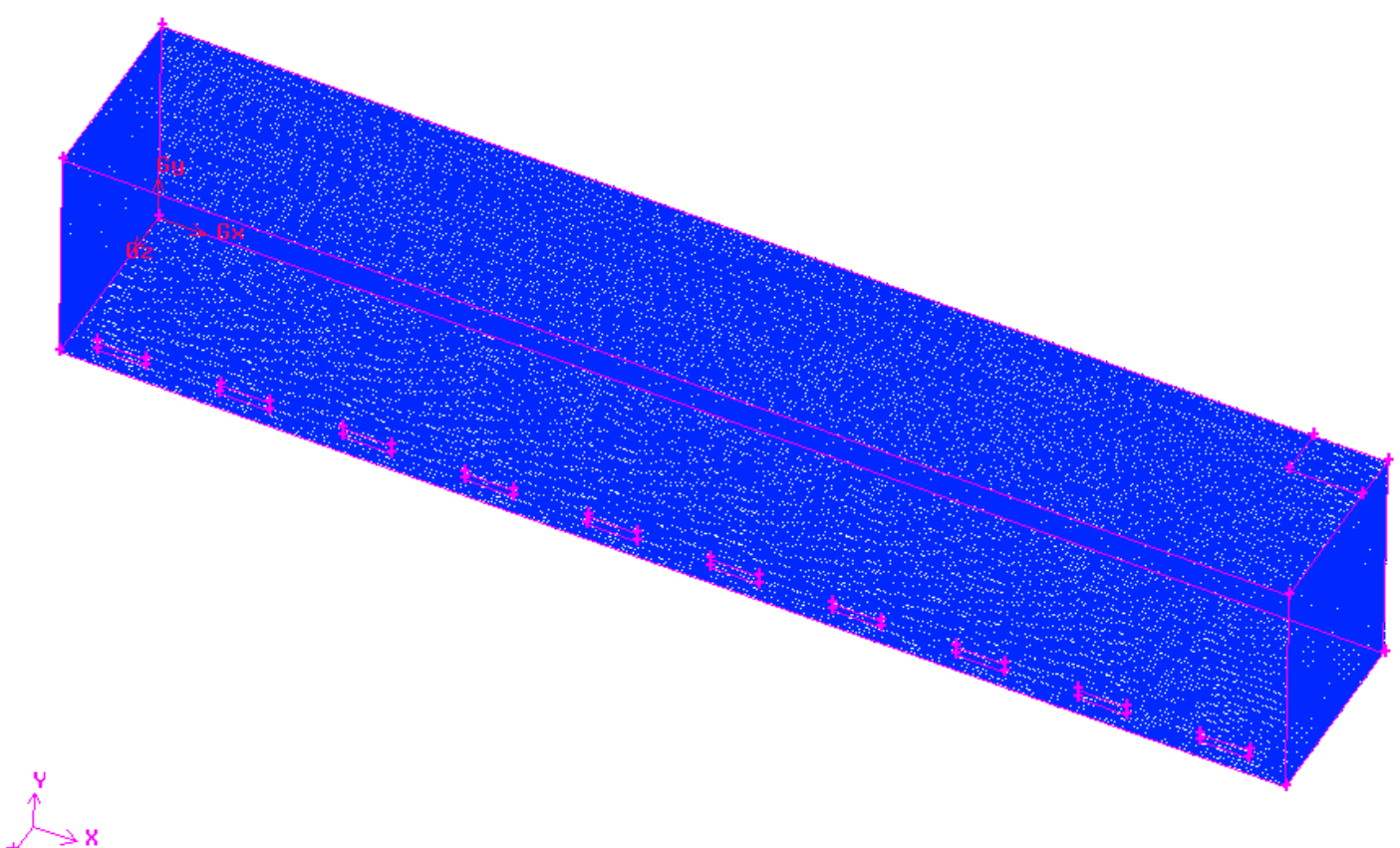

Figure (3) Solution domain and grid used (developed by GAMBIT ${ }^{\circledR}$ )

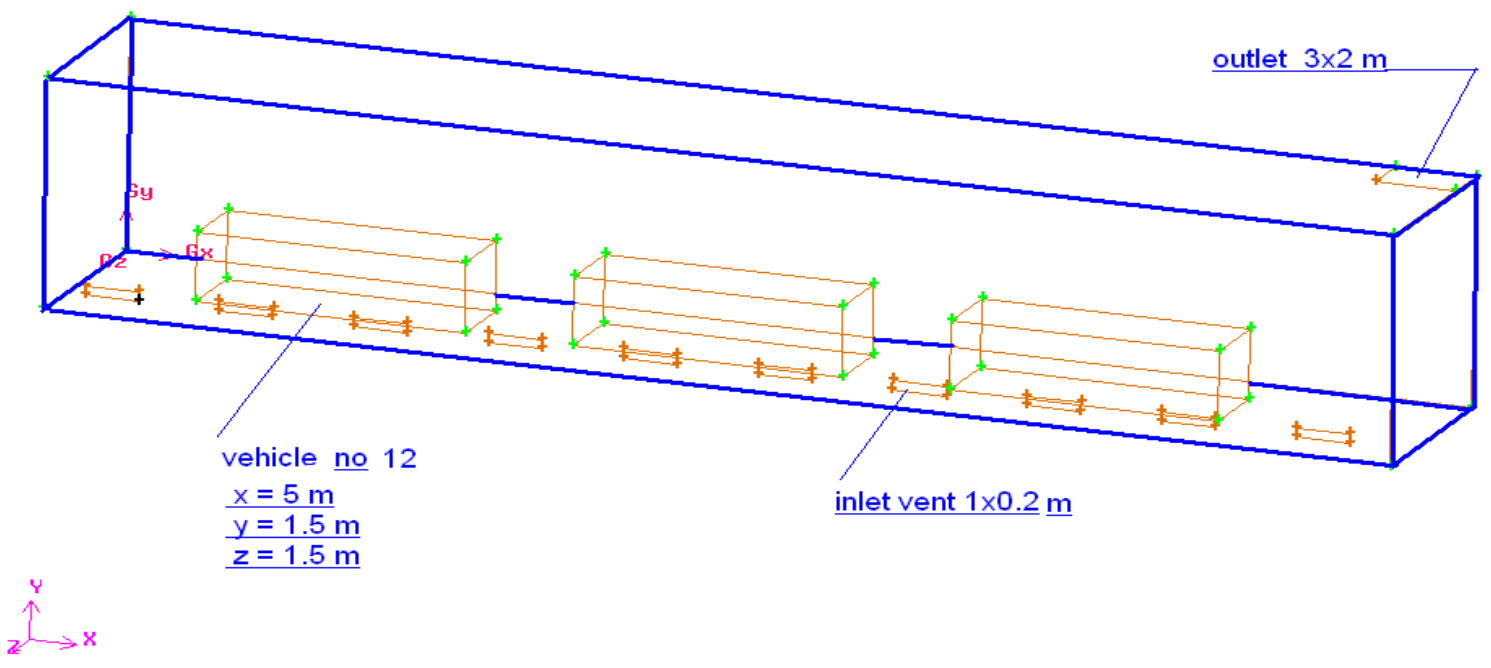

Figure (4) Geometry of the tunnel for halted traffic pattern 


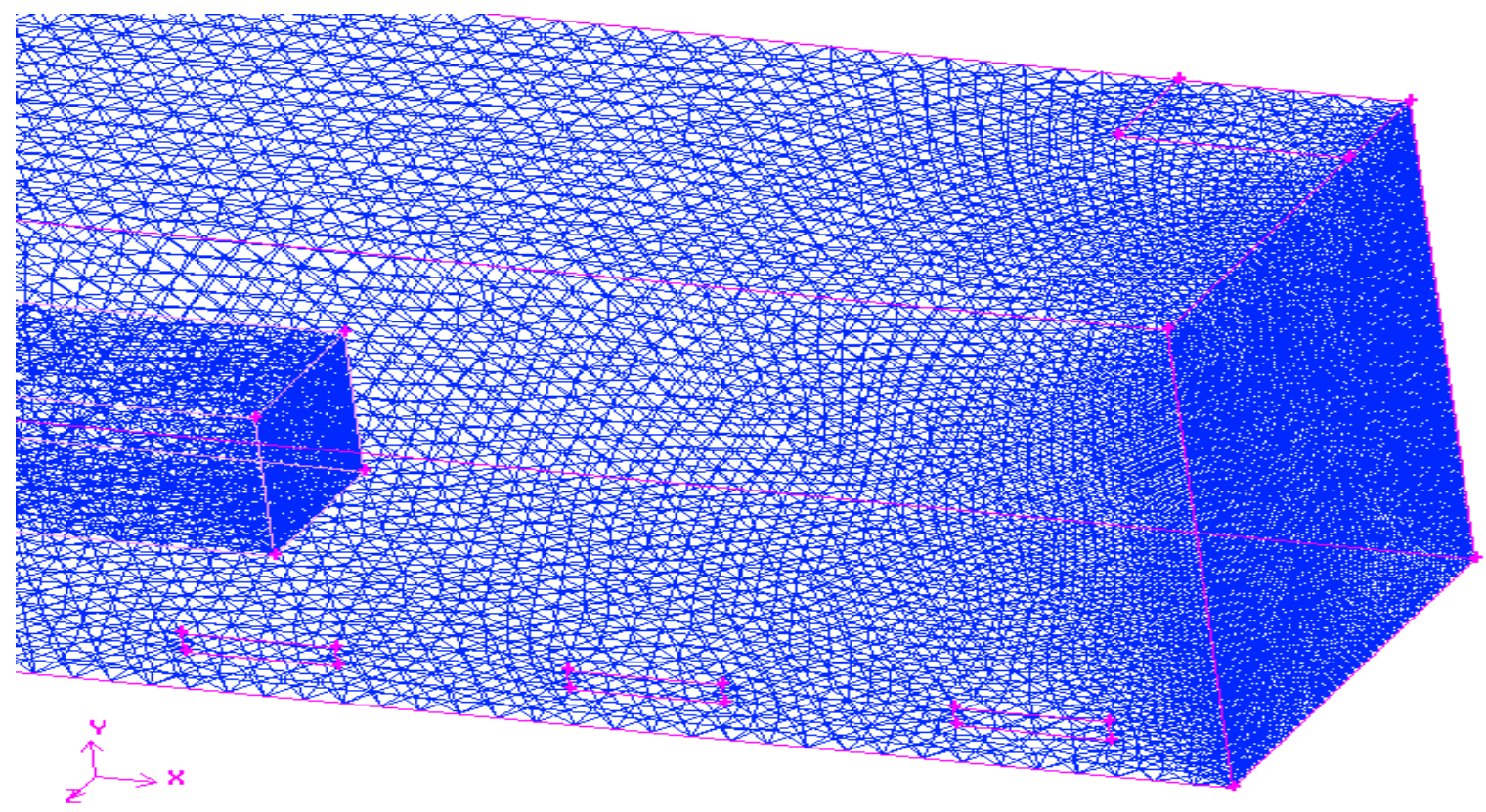

Figure (5) Grid details in the vicinity of vehicles

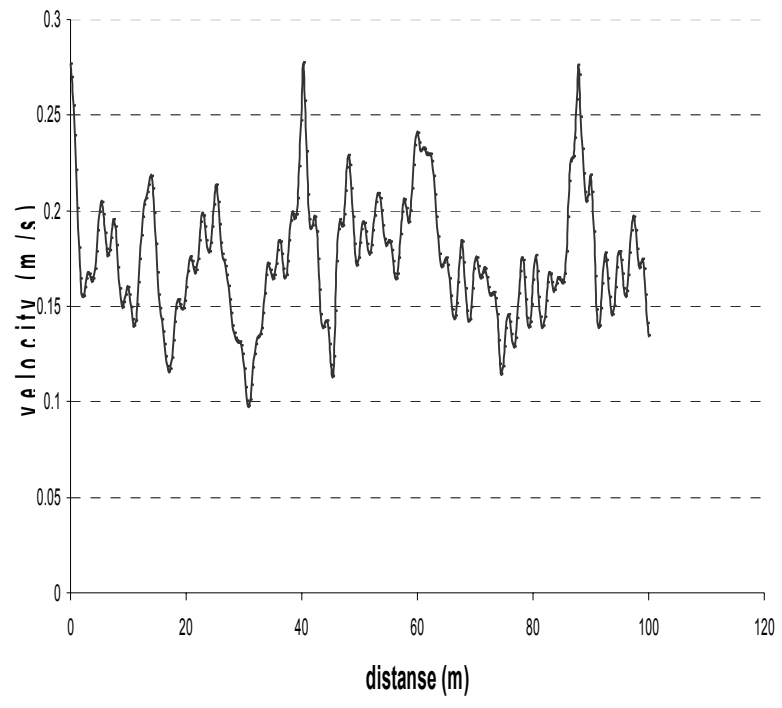

a- at $(y=1 \mathrm{~m}$ and $\mathrm{z}=2 \mathrm{~m})$

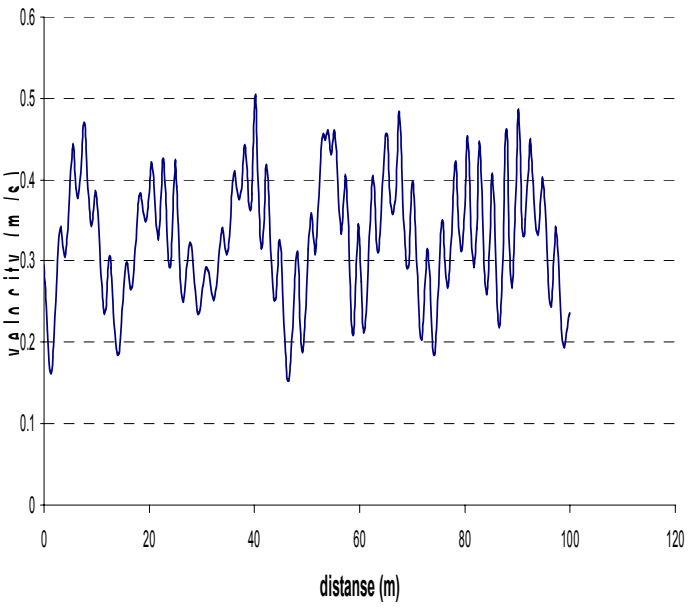

$\mathrm{b}-$ at $(\mathrm{y}=2 \mathrm{~m}$ and $\mathrm{z}=2 \mathrm{~m})$

Figure (6) Velocity distribution for normal traffic pattern and $100 \mathrm{~m}$ exhaust shaft intervals 

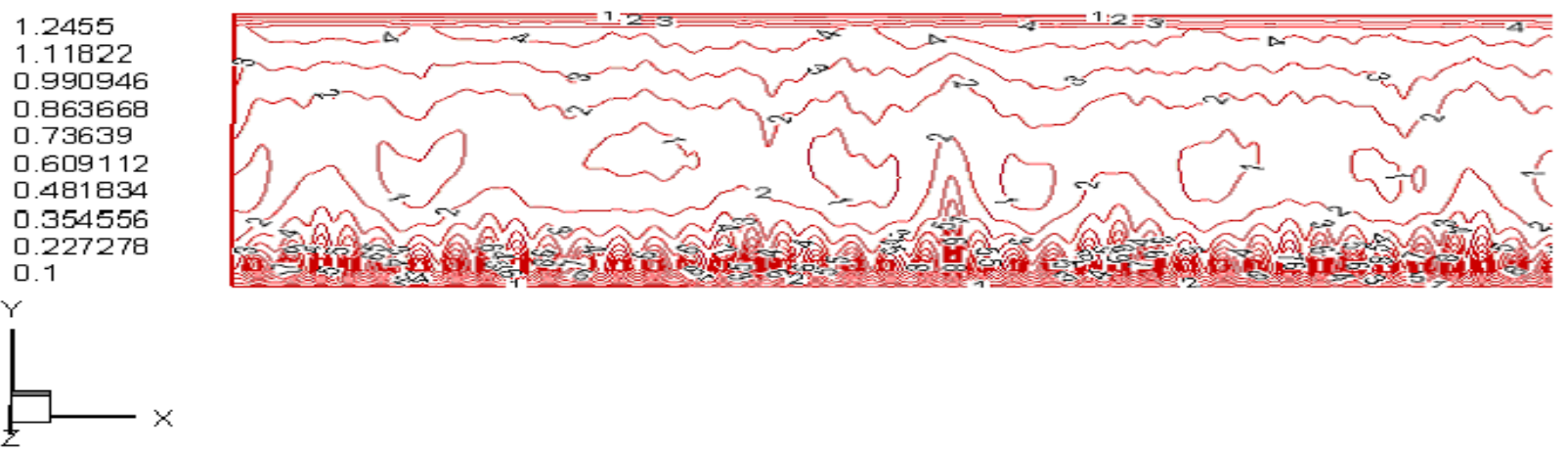

Figure (7) Velocity distribution ( $z=2 \mathrm{~m}$ ) for $100 \mathrm{~m}$ exhaust shaft intervals with values of contours
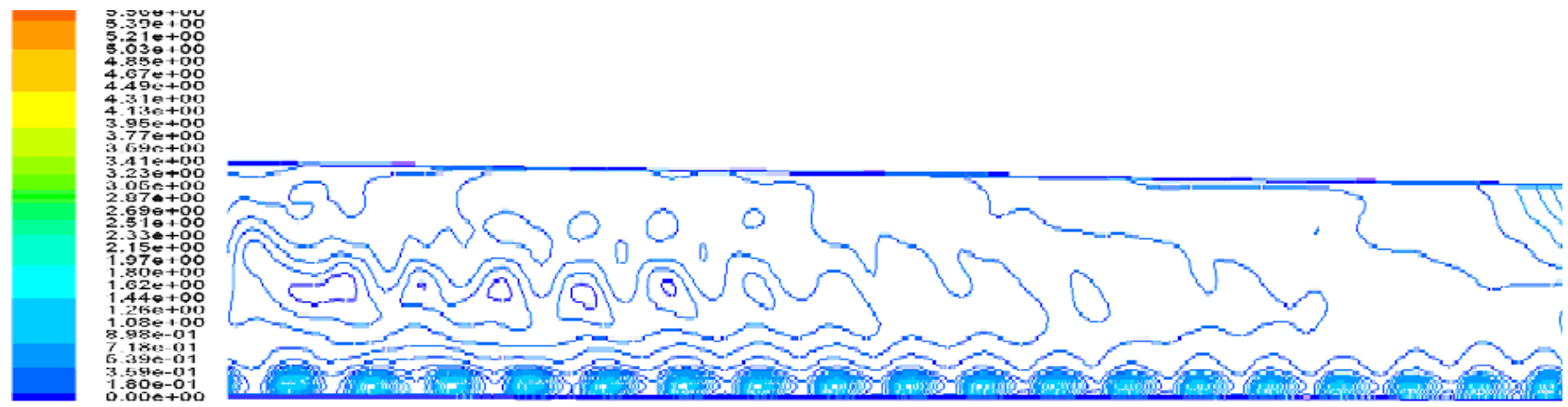

Figure (8) Velocity distribution ( $z=2 \mathrm{~m}$ ) for $100 \mathrm{~m}$ exhaust shaft intervals

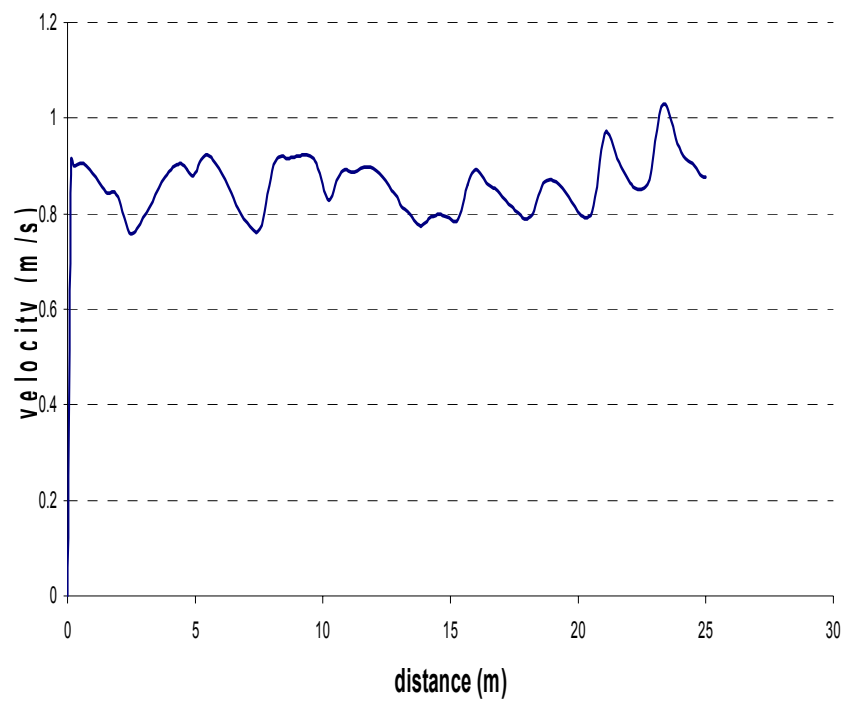

a- at $(y=1 \mathrm{~m}$ and $\mathrm{z}=2 \mathrm{~m})$

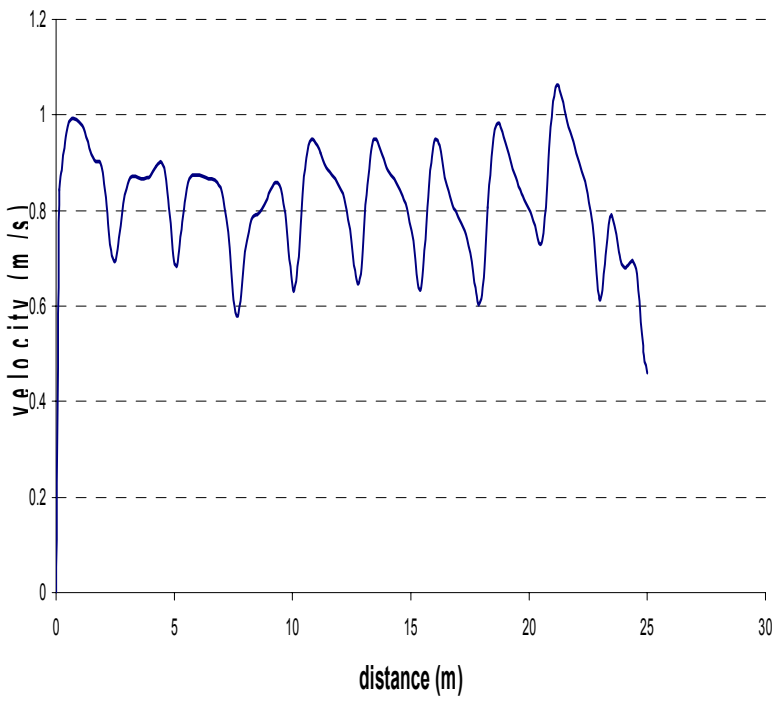

$\mathrm{b}-\mathrm{at}(\mathrm{y}=2 \mathrm{~m}$ and $\mathrm{z}=2 \mathrm{~m})$

Figure (9) Velocity distribution for normal traffic pattern and $50 \mathrm{~m}$ exhaust shaft intervals 

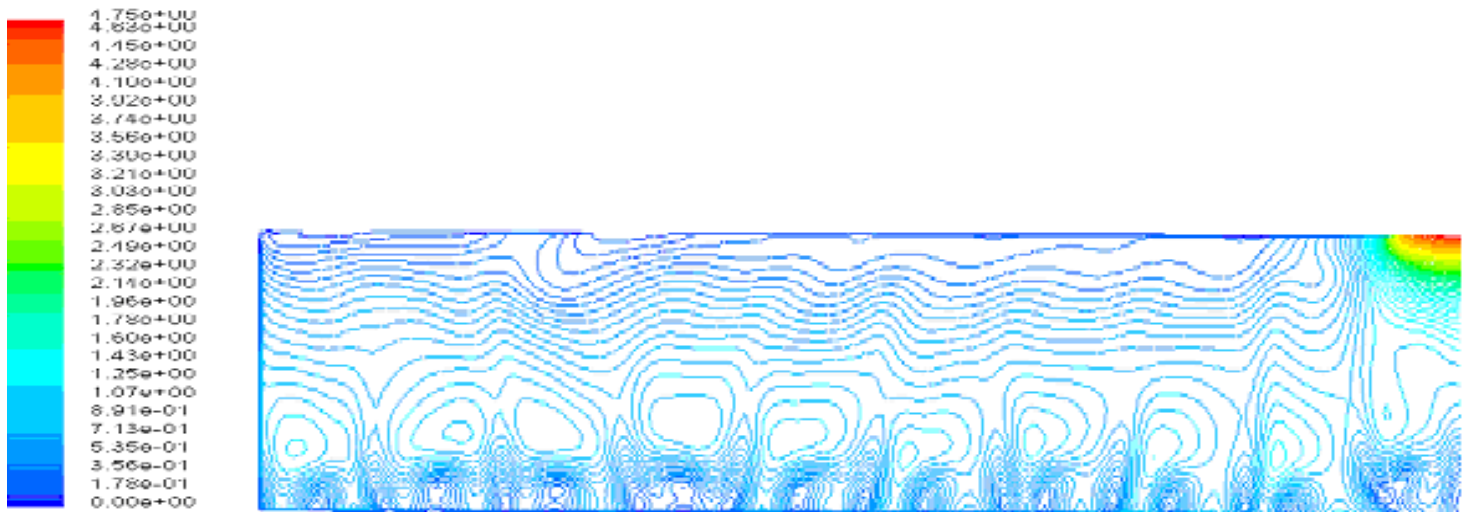

Figure (10) Velocity distribution $(z=2 \mathrm{~m})$ for $50 \mathrm{~m}$ exhaust shaft intervals

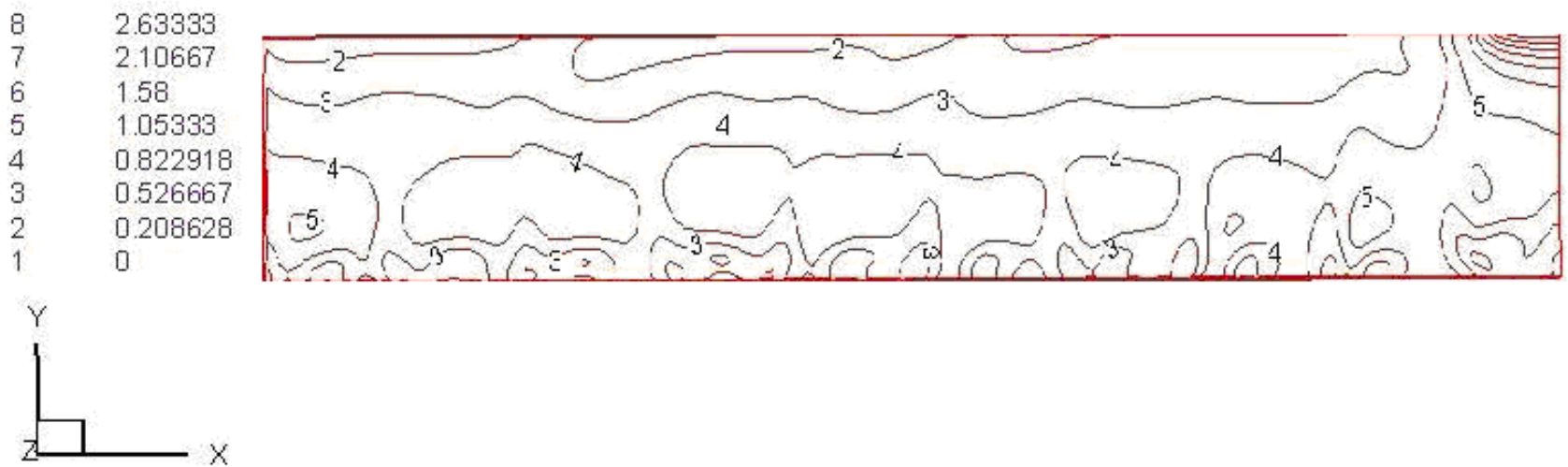

Figure (11) Velocity distribution with values of the contours $(z=2 \mathrm{~m})$ for $50 \mathrm{~m}$ exhaust shaft intervals

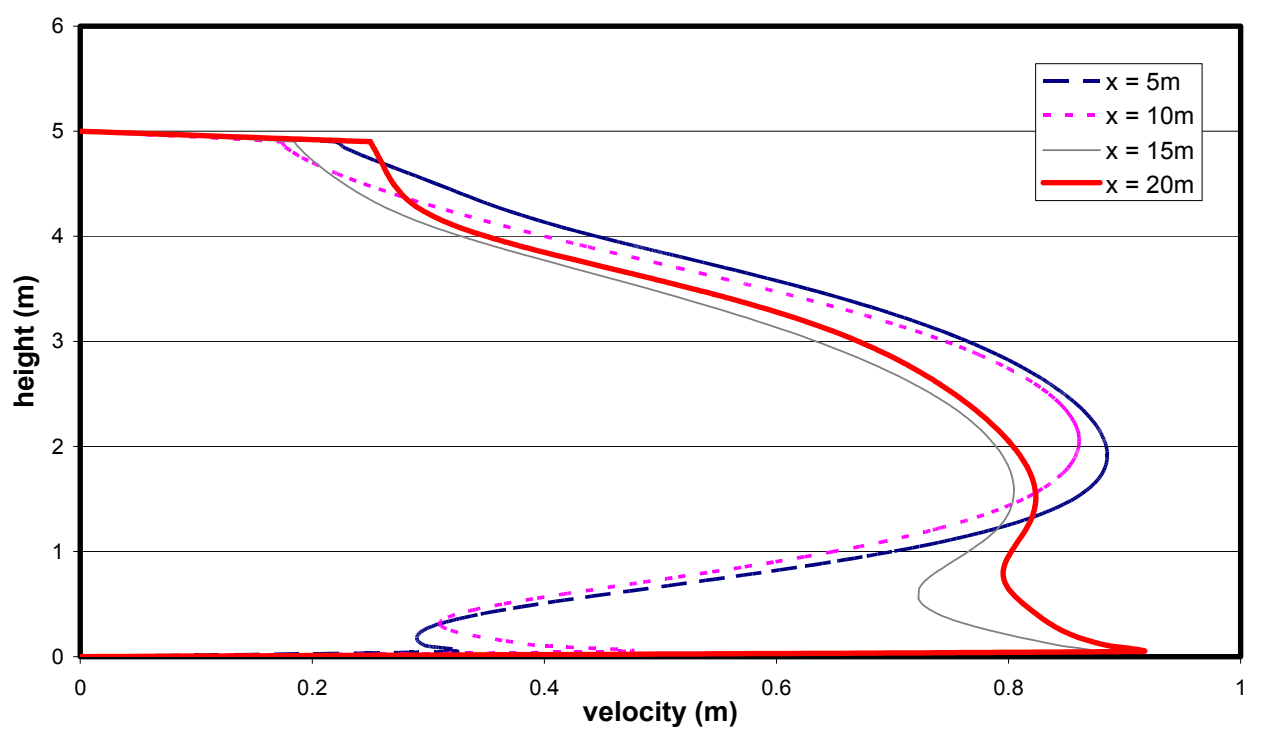

Figure (12) Average velocity at different vertical cross-sections along of the tunnel 


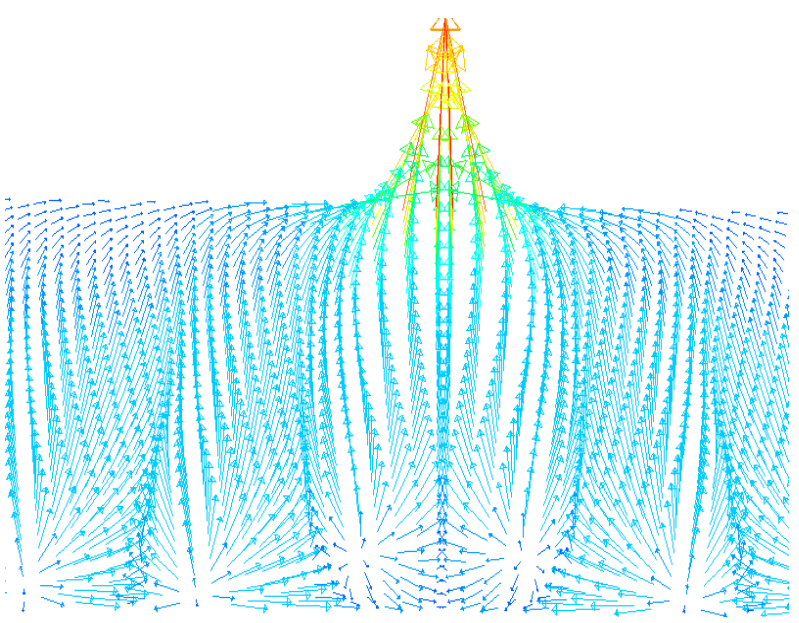

a- Longitudinal cross-section at $(\mathrm{z}=2 \mathrm{~m})$

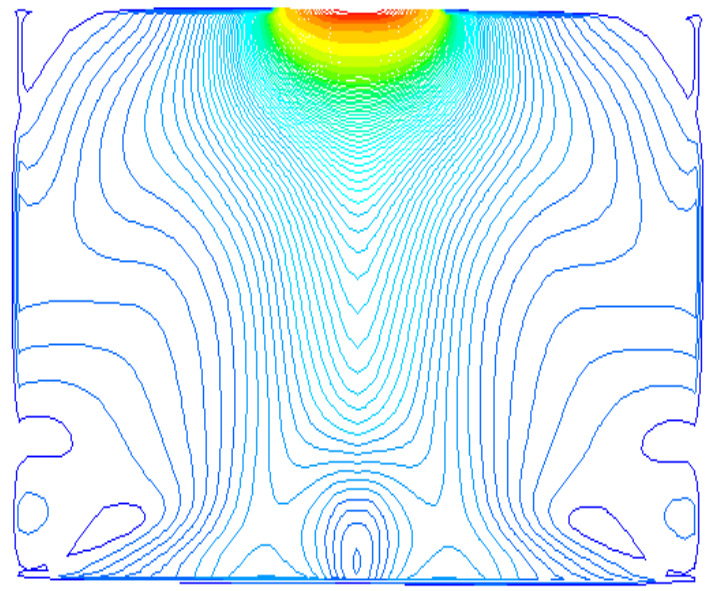

b- Vertical cross-section (at $\mathrm{x}=25 \mathrm{~m})$

Figure (13) Velocity distribution for normal traffic pattern

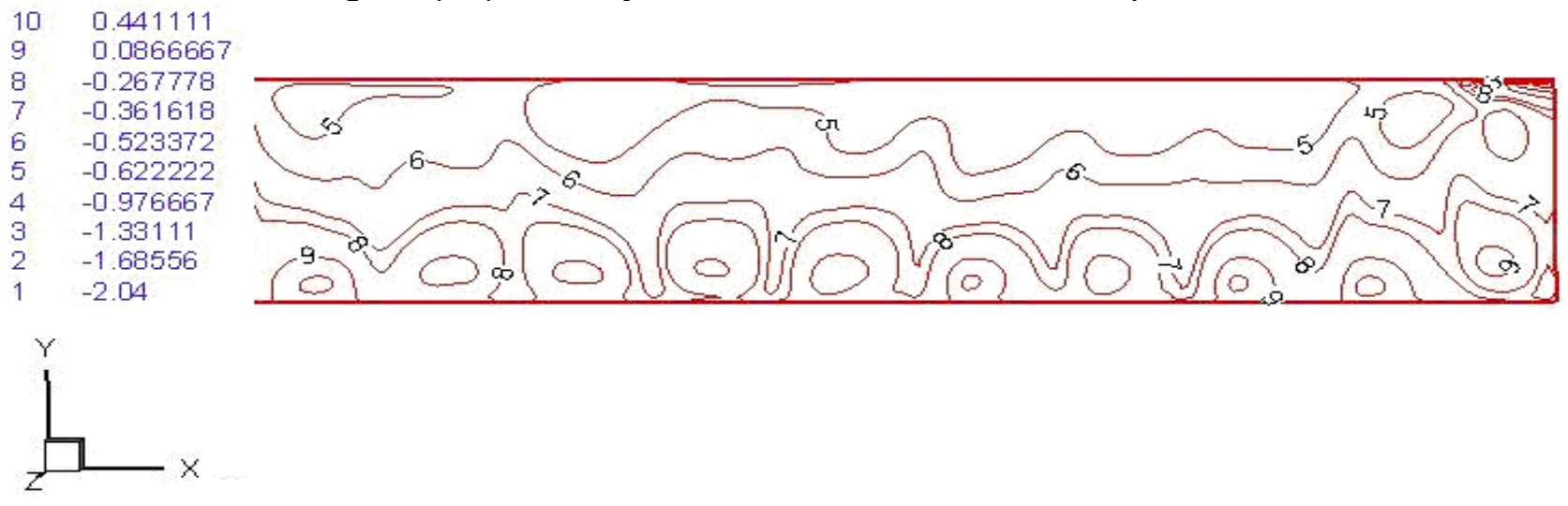

Figure (14) Pressure distribution at $z=2 \mathrm{~m}$ for normal traffic pattern with values of the

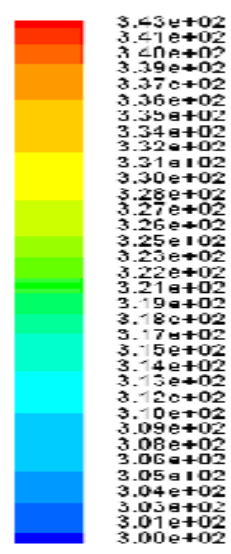
contours at $50 \mathrm{~m}$ exhaust shafts intervals

Figure (15) Pressure distribution at $z=2 \mathrm{~m}$ for normal traffic pattern contours at $50 \mathrm{~m}$ exhaust shafts intervals 


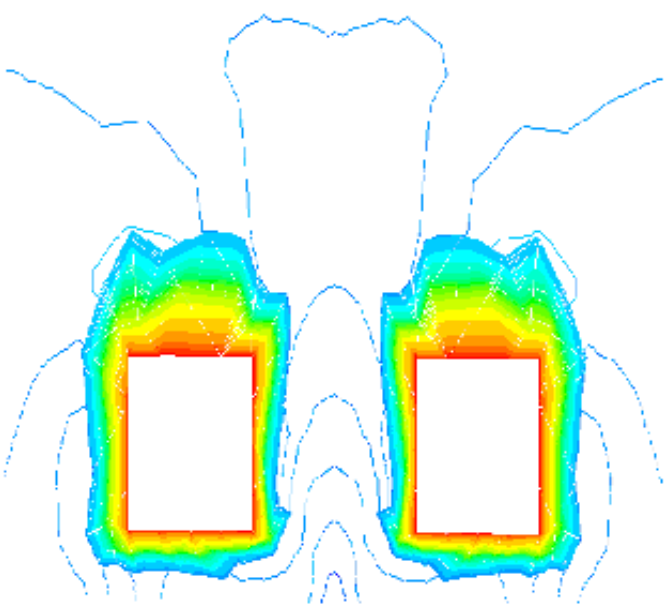

Figure (16) Temperature distribution at $\mathrm{x}=$ $12.5 \mathrm{~m}$ for halted traffic pattern

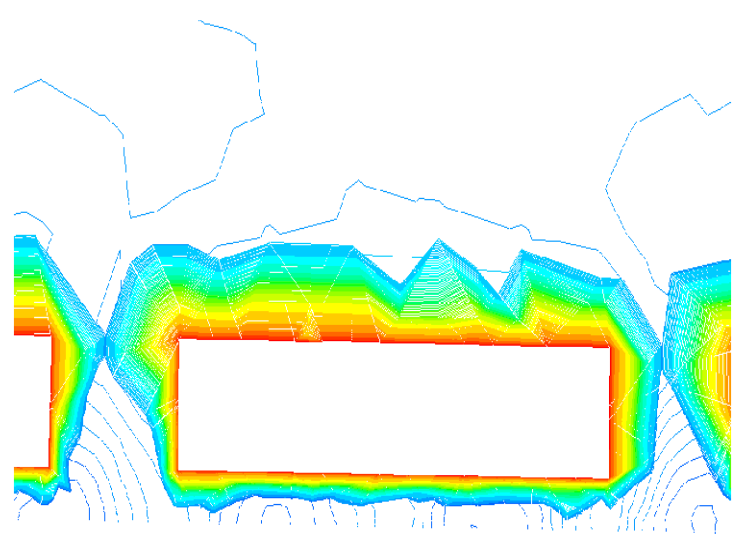

Figure (17) Temperature distribution around th vehicle for halted traffic pattern
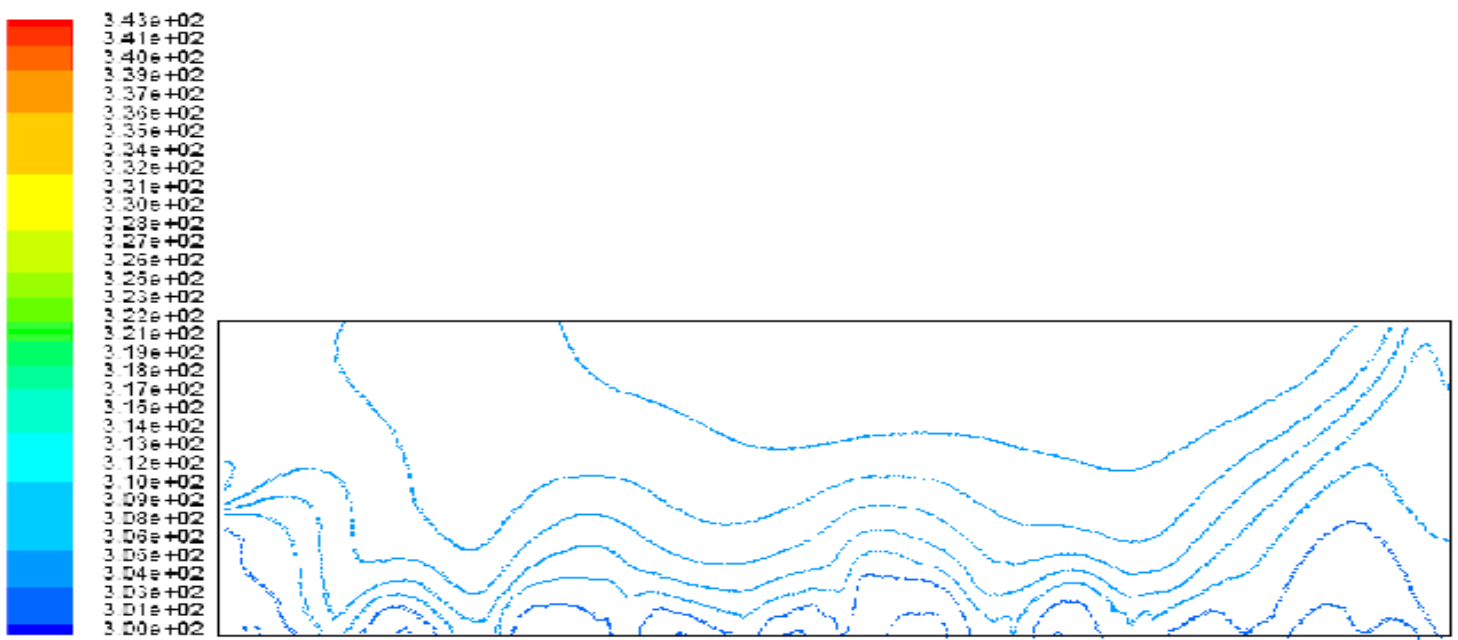

Figure (18) Temperature distribution at $z=2 \mathrm{~m}$ for halted traffic pattern 


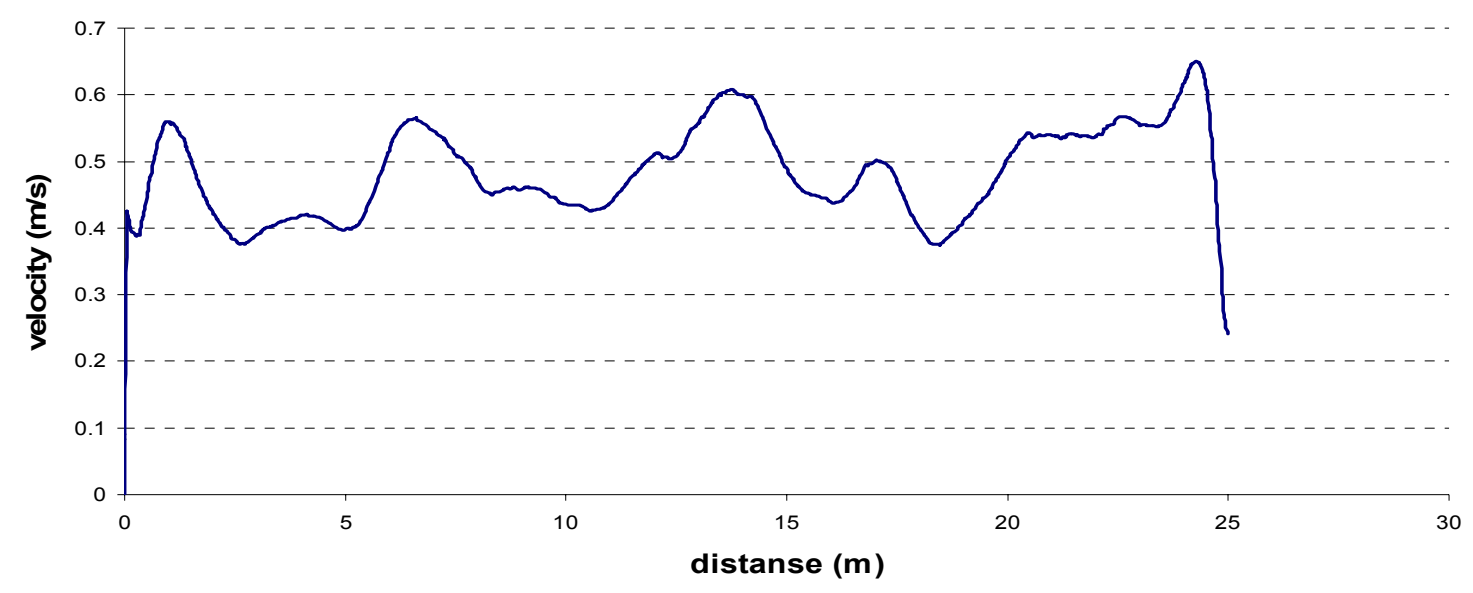

Figure (19) velocity distribution for halted traffic pattern ( $y=1 \mathrm{~m}$ and $z=2 \mathrm{~m}$ )

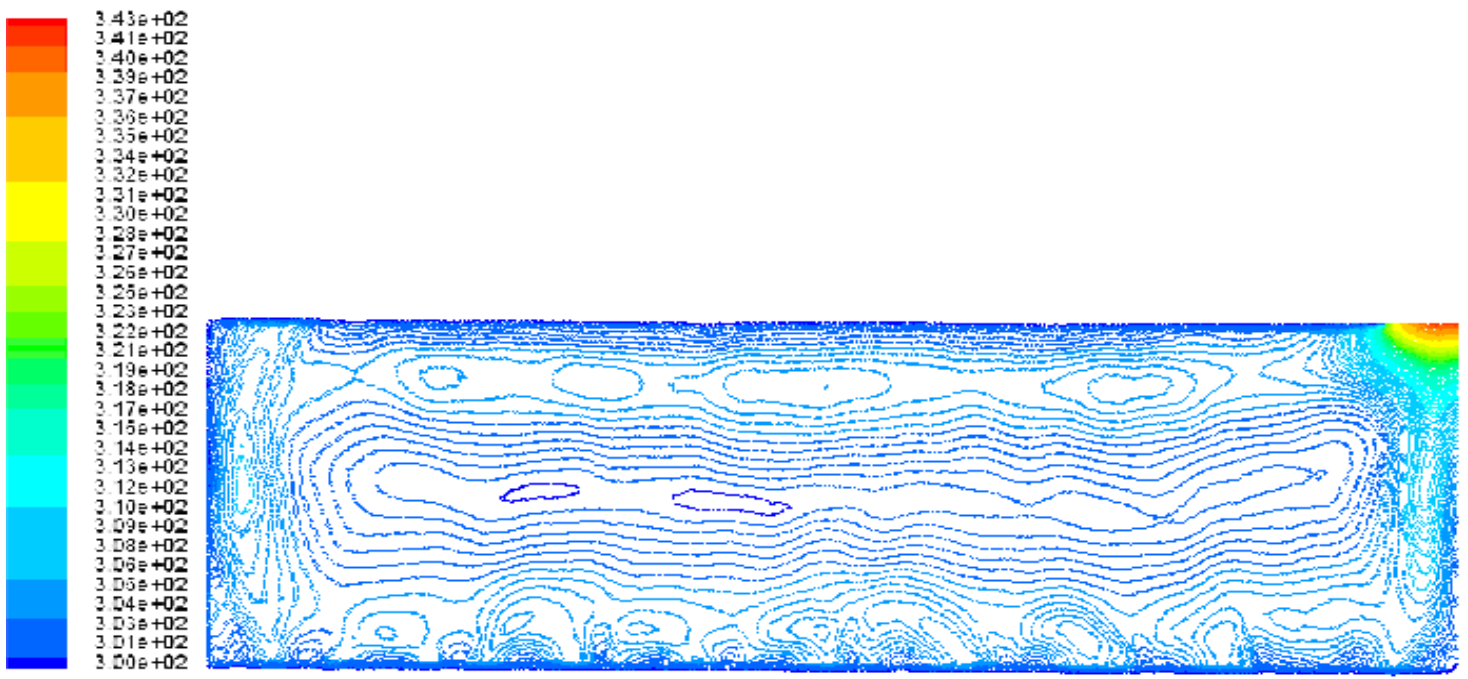

Figure (20) Velocity distribution at $z=2 \mathrm{~m}$ for halted traffic pattern 

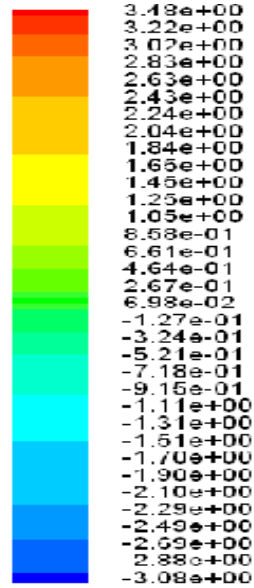

Figure (21) Pressure distribution at $\mathrm{z}=2 \mathrm{~m}$ for halted traffic pattern 